ICONARP

International Journal of Architecture and Planning

Volume 4, Issue 1, pp: 14- 33

DOI: $10.15320 /$ ICONARP.2016120232

ISSN: $2147-9380$

available online at: http://iconarp.selcuk.edu.tr/iconarp

\title{
The Implementation of
} Sustainable Approaches in the Architectural

Design Studio

Developing Architectural

Designs Using the Solar

\section{Envelope Method}

\section{Abstract}

Teaching students the notion of sustainability during their architectural education is of great importance. The architectural design studio course is the most important environment in which theory and practice can be brought together. In this study, the development of architectural design by using the solar envelope method-which can be considered
Fatih CANAN M. Bahadır TOSUNLAR

Keywords:

Solar Envelope, Architectural Designs, Studio

Fatih CANAN

Asst. Prof. Dr. Selçuk University, Department of Architecture, Konya, Turkey

E-mail: fcanan423@hotmail.com

M. Bahadır TOSUNLAR

Res. Assist. Selçuk University, Department of Architecture, Konya, Turkey

E-mail: bahadada@gmail.com 
within the scope of sustainable architecture-was examined in the architectural design studio course in the department of architecture in our university. In the design studio, students had the opportunity to directly observe the impact and use of scientific information that is often difficult to obtain and access. The advantages and disadvantages that appear during the application of this mentioned method was identified based on the observations that were made, and feedback was provided by the students. This method helped the students in conceiving architectural projects in the context of sustainability in a more applied way rather than as a superficial and solely theoretic concept. Through this method, students have gained additional sensitivity regarding solar architecture and perceived its effect on form and space. According to the feedback obtained from students, the most important disadvantage was design freedom. Students found it stringent to be bound to make their designs within very well established boundaries from the early stages. The authors think that the limitations increased creativity and allowed interesting and unusual solutions. The projects were all formed on the basis of the rhythm of nature, which attached more value and meaning to architecture.

\section{INTRODUCTION}

It is an undeniable fact that the construction sector, and hence architecture, plays an important role in the environmental problems that the world is facing nowadays. Sustainability in architecture is of vital importance for the future. The construction sector, where architects are the primary actors, plays an important role in the production of harmful waste materials and extensive energy consumption. In other words, architecture can be an influential tool in introducing sustainability as an important value for society. Architectural and urban spaces in which people maintain their lives have the power to encourage sustainable approaches and ways of living to be accepted by the whole society. Ensuring that sustainable become more widespread in architectural practices depends on the legal regulations, the policies of local administrations and the education provided in architecture schools.

The ability of architects to be able to develop a sustainable design depends on the knowledge they received during their education and their level of experience. The schools of architecture in a variety of countries are making various efforts to ensure they graduate architects who are informed and sensible about sustainability (Wright 2003; De Herde \& Dartevelle 2010; Lefèvre \& D'Orazio 2010; Yannas 2010; Zeiny 2012; Dimitrova 2014). It was also seen that in the schools of 
The Implementation of Sustainable Approaches in the Architectural Design Studio Developing Architectural Designs Using the Solar Envelope Method

architecture in Turkey, the courses regarding sustainability have considerably increased, especially in the last decade (Yüksek 2013). However, what is most important is to use the information given in these courses in architectural design studios which comprise the backbone of architecture education. The young future architects should indeed experience "sustainable architectural design" during their education, especially in architectural design studios, in order to internalize these concepts.

Sustainable architectural principles that are accepted at a global scale and in Turkey constitute the subject of many of the courses provided to students in the department of architecture in Selçuk University. However, knowledge about sustainable architecture is generally shared with students within the context of theoretical elective courses. There is a degree of uncertainty on how this knowledge is shared in applied courses involving architectural design studies. The most important issue to bear in mind is how well the information regarding sustainability can be integrated into architectural design projects. In order to be able to begin applying the information regarding sustainability in a more practical way, a number of problems should be resolved in how architecture education is provided, especially in architectural design studios. These problems can be generally classified as follows:

- $\quad$ Failure to integrate theoretical information regarding sustainability into the architectural design process:

Theoretical information regarding sustainability cannot be internalized by students throughout the design process (Khan et al. 2013). For instance, in case an energy-conscious design is sought, the "energy" concept should be integrated in the design process from the initial stages onwards (Maciel et al. 2007). However, the energy related issues are generally perceived as a problem that should be left to a mechanical engineer who will be a part of the process only at the end of the design.

- Difficulties in wholly grasping technical information and effectively applying them in architectural design:

Certain technical information, which is mostly engineering-related and is not necessarily a part of the architecture education curriculum, might be quite difficult for the students to learn by themselves. For this reason, this information does not guide or shape the spatial design process. For instance, the transfer of basic climatic input data that can 
have a great impact on the energy consumption of the buildings, as well as thermal comfort levels of the residents, such as wind, humidity and exposure to solar radiation in the architectural design is either very superficial, or completely absent. This type of scientific information should be correctly "translated" so that they can be used in the architectural design process (Lenzholzer \& Brown 2013).

- Failure to transfer knowledge learned in theoretical courses into the architectural design process:

In our department of architecture as in many schools of architecture, the knowledge obtained from such courses are not well used in architectural projects. As a result of this, it becomes difficult to obtain sufficient experience in integrating sustainability principles into the architectural design process (Mohammad Taleghani et al. 2011).

- $\quad$ Space and form being excluded from the goals of sustainability:

Space and form are tangible results of an architectural product. Today, under the prevailing conditions in Turkey, architecture is interpreted as a means to show-off by certain groups of people and the difference is sought in the sensation that the forms can result in. This formalistic approach can also be observed in academia, students can easily fall under the influence of this way of thinking (Canan et al. 2006).

Unfortunately, this emphasis causes them to overlook the passive energy gain and energy loss potential of architectrual form . In fact, form has a direct impact on energy consumption of buildings (Granadeiro et al. 2013; Çakmak Yılmaz 2015). Nature has also an important role in the formation of architectural forms (Forwood 1994).

In order to be able to overcome the abovementioned problems, more than the conventional architectural design approaches is needed in the schools of architecture. The instructors have a great responsibility in bringing new teaching methods into practice and in utilizing and combining their own experiences and backgrounds in order to provide a vision of sustainability to the students. In order to accomplish this, an attempt was made within the content of "Architectural Design Studio 4", which is a third year undergraduate course in the department of architecture in Selçuk University. The students were asked to use the solar envelope method developed by 
The Implementation of Sustainable Approaches in the Architectural Design Studio Developing Architectural Designs Using the Solar Envelope Method

Knowles (Knowles 1981). The solar envelope is a method that can be used within the framework of sustainable architectural design and energy-efficient design.

The aims of this study can be listed as follows:

1- Teaching the solar envelope method to the students. Making sure that scientific knowledge that might seem timeconsuming to learn is combined with practice.

2- Determining the effect of the sun on the architectural design. Providing new and relevant experience to the students.

3- Examining the effects of a method that is attempted for the first time in a design studio, determining its advantageous and disadvantageous impacts on the architectural design process and identifying important points.

\section{METHODOLOGY}

The methodology that the students should focus on their project was clearly defined in the first weeks of the course. The studio instructors supervising the studio workload gave a detailed lecture on the solar envelope method within the content of the course. The theory of this method, similar methods that were previously used, books, theses, and up-to-date studies were introduced to the students (Cotton 1996; Siret 1997; Littlefair 1998; Pereira et al. 2001; Capeluto 2003; Knowles 2003; Topaloğlu 2003; Siret \& Harzallah 2006; Canan 2008; Morello and Ratti 2009; Raboudi et al. 2012; Paramitaa and Koerniawan 2013).

\section{Solar envelope concept:}

Knowles describes the solar envelope as follows: "The solar envelope is a construct of space and time: the physical boundaries of surrounding properties and the period of their assured access to sunshine" (Knowles, 2003). The book by Knowles R. L. entitled, "Sun Rhythm Form" provides all details about the principles of the solar envelope method (Knowles, 1981).

The "Solar Envelope" is defined as the boundaries of a construction volume that do not cast shadow on the neighboring buildings located in its close vicinity over a certain time span (Houpert, 2003). The "Solar Envelope" defines the insolation principles in buildings and in the urban fabric (Noble \& Kensek, 1998). Another definition, on the other hand, says that the solar envelope is a space, in which all design solutions are possible and 
formed in consideration of optimizing solar radiation and considering how it casts shadow on the close environment (Capeluto \& Shaviv, 2001). A building designed within the boundaries of a solar envelope will not cast shadows on neighboring buildings located in the vicinity and therefore will not obstruct the insolation potential. The dynamic nature of the sun whose position varies based on time and the seasons, can directly influence architectural and urban forms (Capeluto et al., 2006).

\section{Solar envelope production:}

\section{Stages of solar envelope production:}

In order to produce a solar envelope, the basic parameters of space and time should be well defined:

1-Space Factor: This is the base area of solar envelope. It is defined as the boundaries of the area in which the shadows extend from all directions.

2-Time Factor: The time parameter is defined as the time interval in which insolation is desired.

(Table 1) Shows the production of a solar envelope for winter (December 21, between 10:00 AM and 2:00 PM) on a selected area located in the city of Konya at $37.5^{\circ}$ north latitude. The elevation angle of the sun at 10:00 AM and 2:00 PM is $22.5^{\circ}$. The azimuth angle is $\propto=30^{\circ}$ (at 10.00 AM) and $\propto=-30^{\circ}$ (at 2:00 $\mathrm{PM}$ ). Each stage of solar envelope production is shown in $3 \mathrm{D}$.

Table 1. The stages of solar envelope production

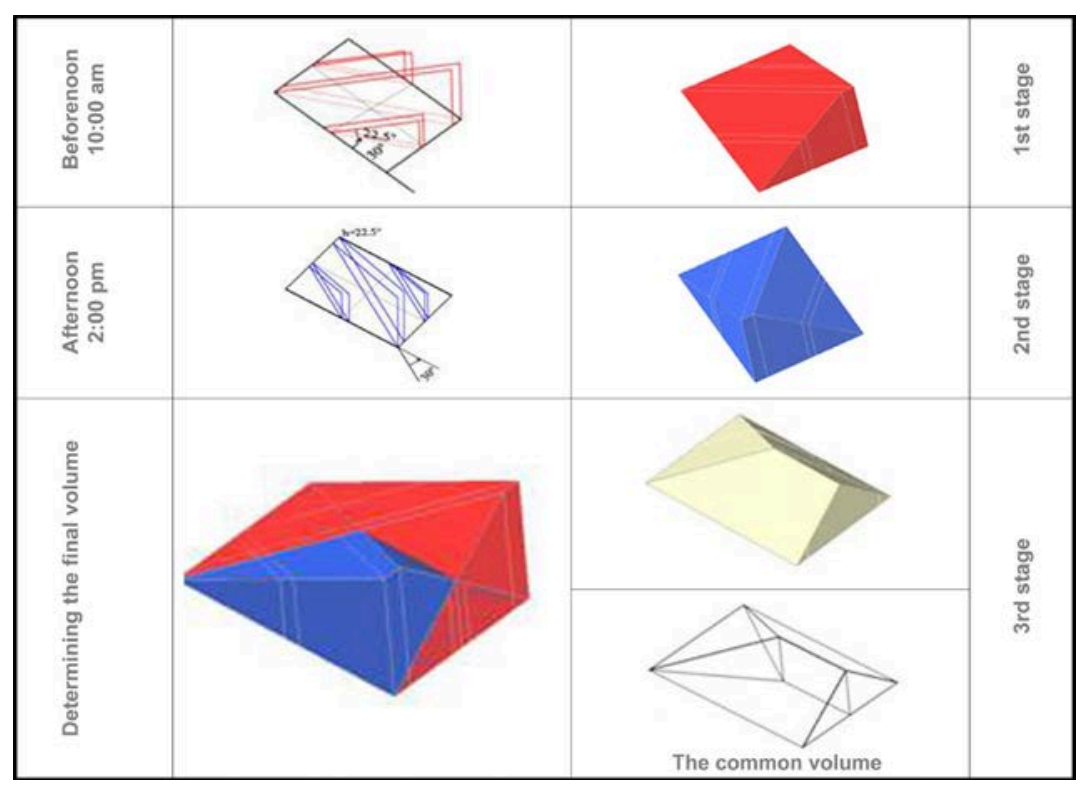


The Implementation of Sustainable Approaches in the Architectural Design Studio Developing Architectural Designs Using the Solar Envelope Method

\section{Students' studies on the production of solar envelopes:}

In order to ensure that the solar envelope method was thoroughly understood by the students, a series of workshops were organized within the framework of the studio course. In the first of these workshops, students produced solar envelope models using a variety of paper and cardboard (Figure 2). For this aim, the student first formed imaginary plots on a base for the city of Konya. They then produced solar envelope models on these areas of different sizes. In the models, the latitude of Konya on December 21 was considered and the coordinates of the sun at 10:00 AM and 2:00 PM were used. Different colors were used to easily perceive solar envelopes produced for different timeslots in one day. It was still a good course exercise, which provided rapid, concrete and effective learning.
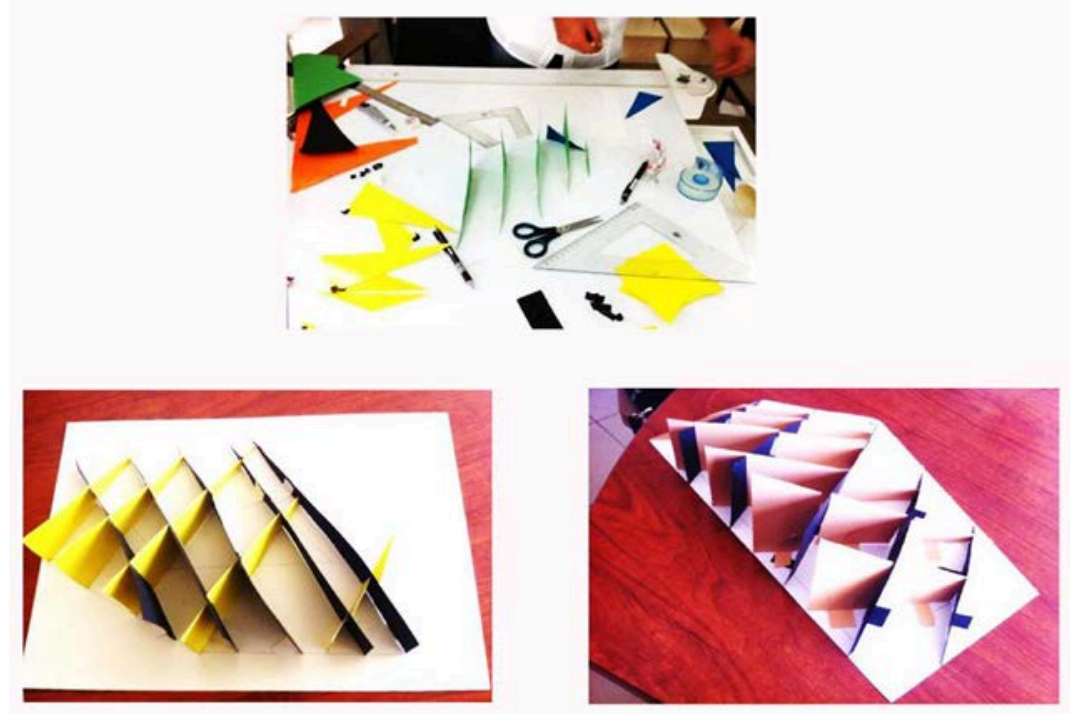

Figure 2. Solar envelope models produced using paper and cardboard

The second workshop of the series aimed to easily produce "solar envelopes" with the three-dimensional working interface of AutoCAD software. The solar envelopes produced for the time before noon and afternoon can be very different from each other, especially in areas with amorphous geometries, resulting in quite unusual volumetric characteristics. This workshop experience showed how difficult it is to find the common volume using two different amorphous volumes without using any software providing three-dimensional working facilities.

\section{Integrating the solar envelope method into the architectural design process:}

The methods used in architectural design processes can be said to generally follow a cyclic path rather than a linear one. 
In order to come to a conclusion, continuous feedback from previous steps is needed. In this dynamic process, the decision is almost always made using a trial and error approach. In the relevant literature, this type of approach is called a direct problem solving approach (Houper, 2003). The insolation problems in the architectural design process are considered very difficult to solve with a direct problem solving method because it is time-consuming (Siret and Houpert, 2004).

The solar envelope method is somehow different in the way it directs the design. It's possible to say that architectural design processes in which the solar envelope method is used are examples of deduction. On the other hand, one can also define the solar envelope method as an inverse problem solving or reverse logic approach. The desired conditions are defined at an early stage (Houpert, 2003). It is requested that the object (architectural form, urban fabric, or any other design product) is shaped on the basis of the intentions (Perrin, 2004).

In the architectural design studio, the solar envelope method was included in the dynamic design processes, with which the students are familiar. The solar envelope method was influential at every stage of the design, and the method was made an intrinsic part of the design process to the greatest extent possible. It was ensured that the students were be assigned a project allowing a flexible working atmosphere so that they were not pushed too far and their productivity was not discouraged.

\section{EVALUATION AND DISCUSSION OF THE DEVELOPED PROJECTS \\ Common approaches and problems observed:}

At the beginning of the term, the students were assigned different areas located in different parts of the city of Konya. The positioning of the areas within the urban fabric, their geometry, surface area and environmental features were all different from one another. The students were expected to make designs including residential, commercial areas and to define their own architectural program (approximately $70 \%$ as residential areas and $30 \%$ as commercial areas).

From the early stages of the design process, the issue that was most innovative and challenged the students was to abandon the two-dimensional plan schemes commonly used. It was a necessity to think in 3 dimensions.

The first sketching phase and initial proposals regarding the general layout plan needed to be carefully studied. As a result of this, it was elaborated with utmost attention where to place open spaces and buildings. They could see especially in the general layout plan decisions that placing buildings too close to each other might result in a loss of construction volume. 
The Implementation of Sustainable Approaches in the Architectural Design Studio Developing Architectural Designs Using the Solar Envelope Method

Generally students attempted to obtain the largest building volumes in order to be more flexible in the later stages of the design. This concern of obtaining the maximum volume became especially noticeable when the aim became to fit as many buildings as possible into the area. The students were not able to determine the height and volumes of the buildings as they wished.

In addition to these, the majority of the proposed projects made an attempt to integrate the new design with the urban fabric. Students reflected well on the design approaches to prevent social isolation, which is one of the main goals of sustainable cities. Social and functional mixity were important keywords on the design process.

After established their general layout plans, students began to work on the solutions of the internal problems on a limited space. They cut the obtained volumes horizontally and created planes corresponding to different floors. It was observed that the formation of vertical circulation core providing access to residential units at each floor (stairs enclosures and elevators) was one of the biggest design problems that the students faced in the entire studio process. In the mass produced by using solar envelopes; the slab surface area of each floor gradually decreases 22 with height and the vertical circulation core should be positioned by taking this effect into consideration.

As the number of floors decreased in buildings towards the north, it was considered suitable to not provide access to buildings in this direction. Access to the buildings at higher floors was more or less from the southern direction. This is a good design decision because the prevailing wind direction in Konya is north.

Due to the upward gradual decrease in surface areas, different plan layouts were required on the highest floors. In order to overcome this design problem, students had to produce unconventional solutions and therefore new planning schemes outside of the typical residential plan types were pursued. Terraces that were formed due to the gradual form of the buildings allowed for the use of green roofs and edible landscape.

Although the seasons where heating is needed became somewhat important for the design, in the proposed designs, the summertime comfort conditions were also attempted to be satisfied. Students proposed the use of mobile or fixed solar breakers in order to ensure summertime comfort.

\section{Examination of some selected student projects:}

In the project developed by Abdülhamid İçöz on area no. 1 , a total of three buildings were fit in the area. Different stages of obtaining building volumes using solar envelopes are shown 
in (Figure 3). The building block located at the northern tip of the area is composed of commercial and residential functions. There is a small inner valley in the building form obtained by using solar envelope method. The building is composed of gradual terraces that faced each other, and has a mixt function. The ground, first, second and third floors are composed of commercial spaces. On the fourth and fifth floors, there are studios and other apartments. On the higher floors, where the surface areas decreased due to solar envelope, duplex apartments were designed. Two blocks located in the south have a solely residential function.

Figure 3. The project developed by Abdülhamid İçöz

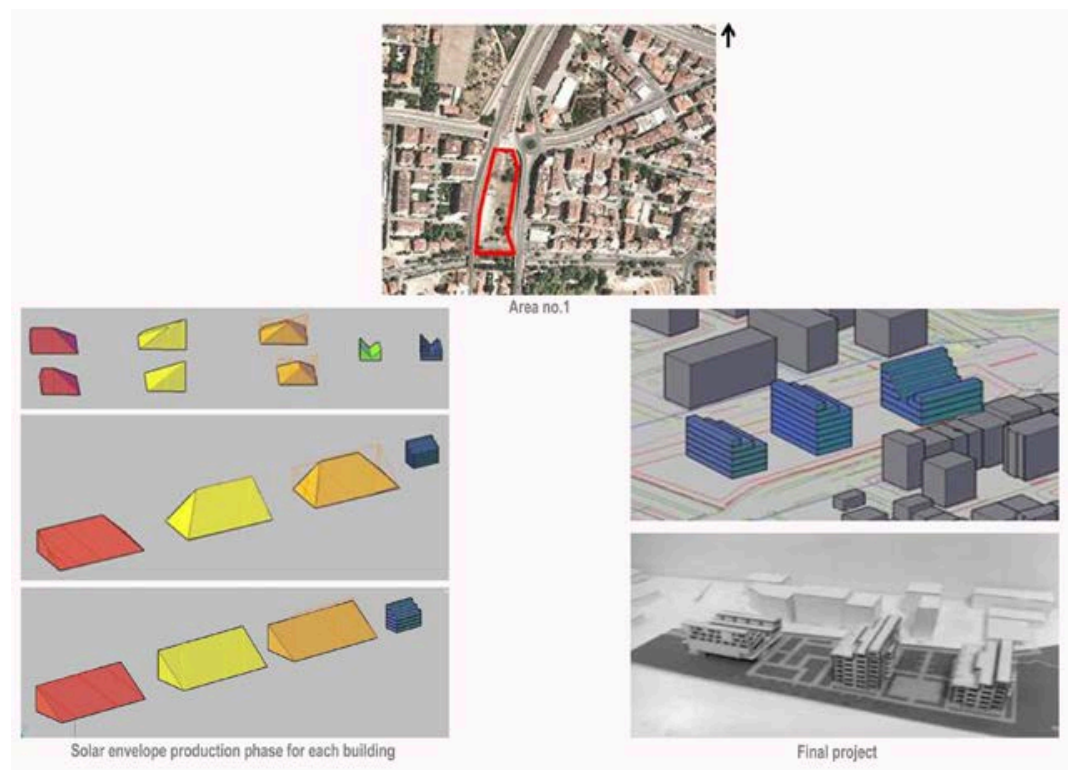

The project developed by Ali Riza Kapkap on area no. 2: the site is located in an urban redevelopment area. Therefore, it was an interesting architectural design attempt with the use of the solar envelope method, as redevelopment areas are generally formed with financial concerns.

The project is composed of a residential building and a commercial block located nearby. Although this area is wider than the area no. 1, the student took no chances and designed fewer buildings (Figure 4). The design included a car park and a supermarket on the ground floor of the residential building, which has access from two different directions (north and south). The apartments are accessed via long hallways. The stores located in the commercial building were not designed to be exposed to direct sunlight. Therefore, the commercial block was not taken into consideration while producing the solar envelope to obtain the volume of the residential building. 
The Implementation of Sustainable Approaches in the Architectural Design Studio Developing Architectural Designs Using the Solar Envelope Method

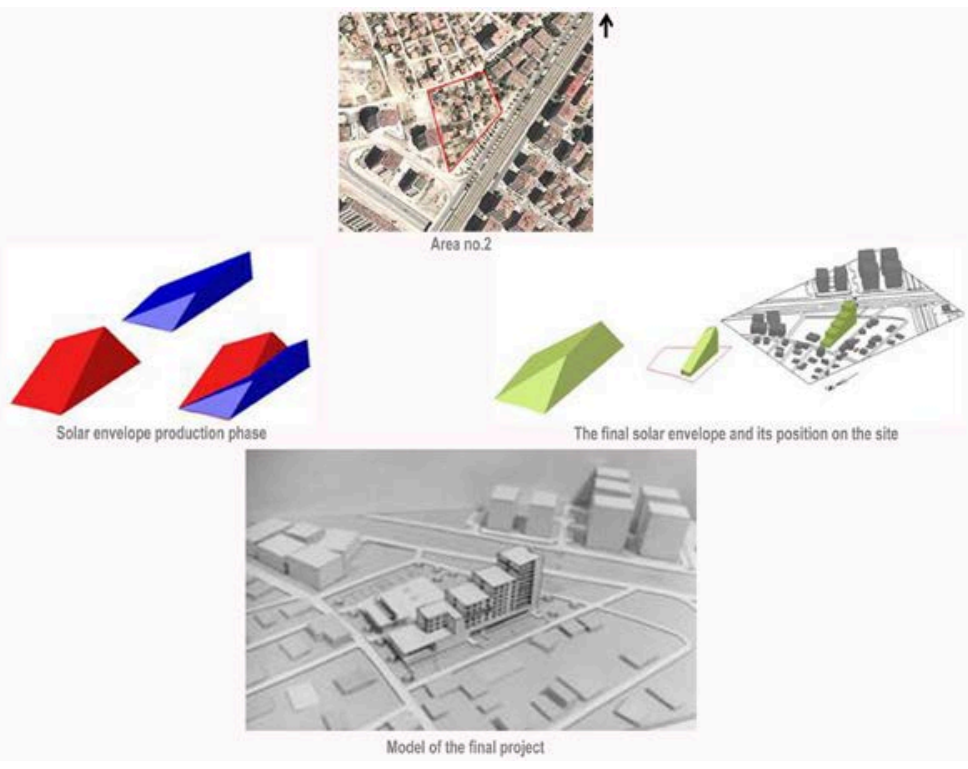

The project of Abdullah Selçuk in area no. 3: The area is located in an urban zone in transformation. One of the most remarkable features of this project is the square centrally located that contributed to create a public space. There are three buildings surrounding this public square (Figure 5). At the 24 ground floors of the buildings, there are social and commercial facilities such as shops, restaurants and cafes (Figure 6). In the south part of the area, open spaces with landscape arrangements are organized for public use.

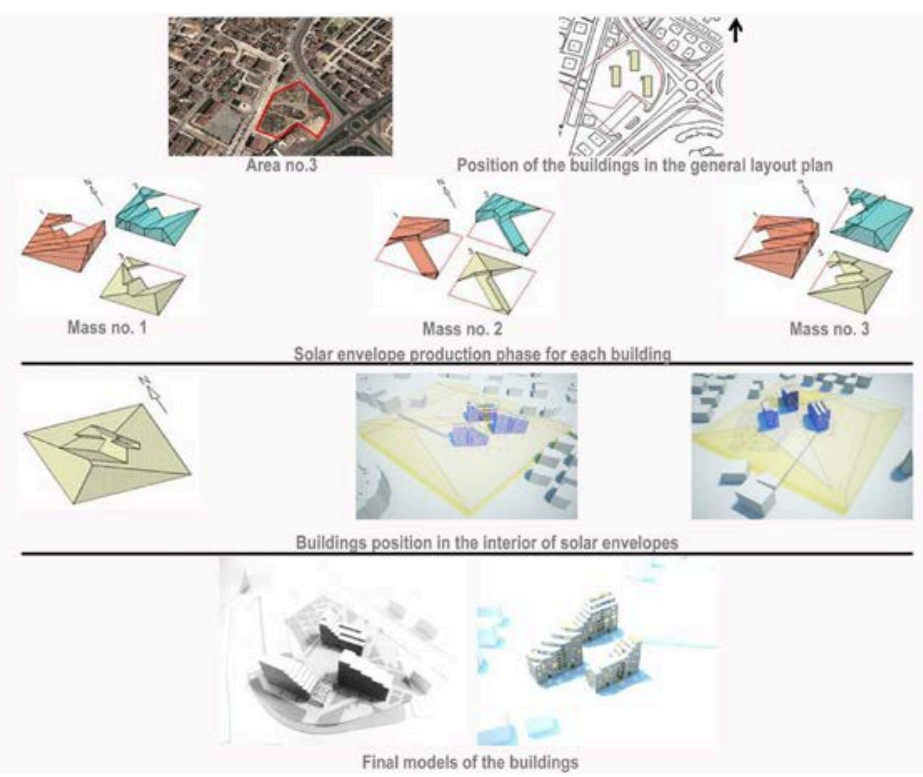

Figure 4. The project developed by Ali Rıza Kapkap
Figure 5. The project developed by Abdullah Selçuk 
Figure 6. The project developed by Abdullah Selçuk (Plans of different floors in the B block)
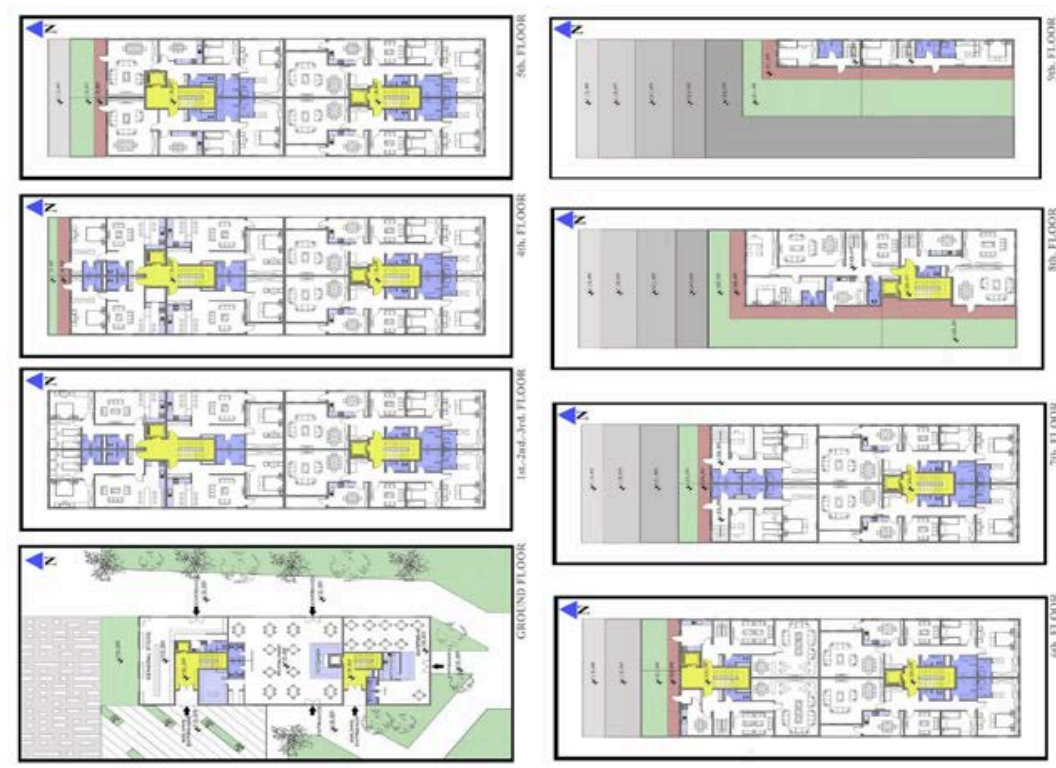

\section{Students feedback:}

In the final week of the design studio, students provided their feedback about the information they were given during the term and the methods they applied in the architectural design studio. The studio instructors considered it important to determine the negative and positive views of the students regarding this method that was implemented for the first time. This feedback was considered to reveal important hints for similar projects in the future and indicate some problems that might have escaped. In this context, students were asked a number of open ended questions. Students were asked to freely express themselves. The most interesting answers given by the students are listed below under each relevant question.

What do you think about the solar envelope method? What is it that the method brought to your projects?

-The solar envelope method showed us how knowledge related to the sun can be used in our projects. Until today, we have always been asked to research about prevailing winds, negative winds, temperature graphs, precipitation graphs and sun diagrams for environmental impact analysis and to include all these aspects into the relevant drawings. However, I never fully understood why we put all this material into our presentations, or even why we carried out all these analyses because I could not see how the analysis stage affected my project. For the first time, I am actually able to see the reflection of the results obtained from the environmental analyses on my design. I understood that the sun had a significant impact on the design beyond where it rises and where it sets. 
The Implementation of Sustainable Approaches in the Architectural Design Studio Developing Architectural Designs Using the Solar Envelope Method

- The solar envelope method taught me to consider others who will not use my design. It limited my urge to design random things and helped me organize my design considerations. It made me happy to be able to say "we are designing residential and commercial facilities, but we are doing this in an entirely different way".

- In the initial stages, it found it difficult to apply the method to my project. However, after a while, when I better understood the method, I started seeing it benefits. This method changed my perspective on architectural design. It forced me to think about the right of insolation for people living in the close vicinity. Another interesting benefit of the method is that it helps produce the form directly.

- This new method helped us take a concrete step in architecture to protect natural cycles.

- The solar envelope method offers an architectural approach that looks after the environment out of the boundaries of usual contractor mentality. It helped us take care of the environment as much as we care for ourselves.

- I never paid so much attention to the environment in my previous projects. Thanks to this project, I learned how to make new designs without ignoring the environment. This method forced us to design even the distances between different buildings, while finalizing the general layout plan. This method also had an influence on the organizations of the squares and pedestrian axes in the design area.

\section{What do you think are the limitations of the solar envelope method?}

- I had the opportunity to determine the building forms in the projects in which I have thus far participated. In the project that we carried out using the solar envelope method, the form is shaped in the initial stages and all of our plan-related solutions had to be dependent on these forms.

- The building volumes decrease towards upper floors, due to the inclination angles of the sun's rays. This situation requires completely different planning solutions on the upper floors. Although this might seem like an advantage at first, it made it considerably harder to design circulation areas.

- While organizing the general layout of the design, we had to come up with the right locations of the masses. Otherwise, improper positioning results in serious losses in floor surfaces. 
- The solar envelopes needed to be reproduced even when I created the smallest projection during the planning stage. This meant I had to restart the whole process all over again.

-The limitations of the method become apparent only when one needs to decide the floor height and form. It does not have significant limitations from an architectural perspective. Since architects need to have the ability to make designs in all sorts of environments, I do not consider it disadvantageous to try to come up with solutions within the boundaries of this method.

- It is not easy to make corrections throughout the project. A correction can take the project to the beginning of the whole process.

- The design areas decrease significantly on the upper floors. In spite of this disadvantage, the solar envelope method gave us the opportunity to design new spaces such as terrace floor gardens and encourages us to consider these types of spaces. The method suggests the use of new living spaces in our projects.

If the project subject was designed using a different technique other than the solar envelope method, what would your project be like?

- I would have more freedom in terms of heights and the distribution of masses over the used building plot. In addition, it would be easier to cope with the functions.

- If I need to make a comparison on the basis of general layout plans, I can easily say that buildings were closer to each other in my previous projects. In addition in these projects, the open and semi-open spaces were not properly organized. Thanks to the solar envelope method, my suggestions regarding the positioning of the buildings and the design of other buildings were more consciously made rather than randomly.

-If I did not use this method, I could have suggested the use of higher buildings without considering the buildings in the close vicinity.

Would you consider using this method in your projects in your future career path?

- It might be impossible to complete a project solely using the solar envelope method; however, it can be applied in parts of a project.

- If I am given an opportunity to carry out an ecological architectural design project, I would most definitely use the solar envelope method. 
The Implementation of Sustainable Approaches in the Architectural Design Studio Developing Architectural Designs Using the Solar Envelope Method

- When I consider the market conditions that I became familiar with during my summer practice, I find it quite hard to find an opportunity to apply this method anywhere apart from school projects, because the number of floors and building density cannot be defined randomly when the solar envelope method is used. Clients want to obtain the maximum economic gain out of their land, within the limits of legal regulations. For the solar envelope method to be more applicable in the future, all the architects should be aware of the importance of such design approaches. Maybe then, the laws and regulations regarding construction changes and these environmental design methods can become more applicable.

- I can use it in my future professional life. I can also be an architect that creates very interesting solutions.

After the examination of the responses given by students, it's possible to say that the majority of students were satisfied to applicate the solar envelope method in their project. The experimentation of the method in the design phase was a great gain for both students and for teachers.

The most important feature of the solar envelope method is that it can determine building forms in the very early stages of the architectural design process. It was observed that students gained a significant architectural awareness while attempting to attain an "architectural meaning" to the volumes, which are only some geometrical forms in the initial stages of the design process. The majority of the students were observed to learn how to tackle this new method and consciously use it, offering a completely new way to look at design.

The student feedback clearly shows that most students are willing to use this method in their future professional lives.

Finally, one can discuss a "creative limitation" regarding the solar envelope method. The limitations increased creativity and allowed interesting and unusual solutions. The projects developed and proposed within the framework of this exercise were all formed on the basis of the rhythm of nature, which attached more value and meaning to architecture.

\section{Acknowledgements:}

We would like to thank the students who participated to the "Architectural Design Studio 4" course in the autumn session of the 2013-2014 academic year. Among these students, we would like specially mention the following names: Abdullah Selçuk, Ali Rıza Kapkap, Abdülhamid İçöz, A. Mennan Yıldız, Ayhan Avunan, A.Emre Sözel, Üsame Koç, A. Gürkan Arslan, Sıddıka Yeșilkaya, Dilfuza Shainova and Salim Karagözoğlu. 


\section{CONCLUSIONS AND SUGGESTIONS}

The ability of an architect to be able to develop a sustainable design depends on the information he/she received during his/her education. The schools of architecture should give information regarding sustainable design to ensure they graduate architects, who are informed and sensible about sustainability, as a part of their social responsibility. In order to accomplish this, an attempt was made within the content of the "Architectural Design Studio 4" and students were asked to carry out a project using the solar envelope method. Therefore, the students were given the opportunity to learn and apply a scientific method that is normally not taught in the architectural design studio in our school and use this method for their projects as a tool for design. As they worked with a method resulting in concrete gains in terms of ecological architectural design, they were especially motivated. Students acknowledged the fact that it was important to be given an opportunity to have deeper insight about sustainable architectural design in the design studio environment. The subject of insolation did not remain just as a theory, but could influence architectural projects. It is especially important that they worked with the solar envelope method on real building plots in the city of Konya and within a scheme based on realistic architectural requirements.

Owing to this studio study; the concept of sustainable architecture, a popular term frequently mentioned in national and international architecture platforms, was no longer from the students standpoint an inaccessible concept implemented by only a few architects. They also produced tangible sustainable architectural products. In addition, students felt privileged as they were given the opportunity to learn more about sustainable architecture and create a design. The authors believe this consciousness that the students gained at the end of this exercise will have an influence on future architectural design projects in which the students will participate.

The biggest concern of the students, on the other hand, was that this and similar methods and design approaches were unlikely to find widespread application under the current market conditions due to financial concerns. We believe that this concern is partially valid. Unfortunately, our students are mostly adversely affected by the actual professional architectural practices whenever they have an opportunity to become more closely familiar with them. They were suggested to be well equipped and courageous as a means to liberate themselves from these negative thoughts. The architectural design studio course that was carried out using the solar envelope method has indeed become a courageous attempt during the project production process. Breaking the resistance against change is an important responsibility for future architects. 
The Implementation of Sustainable Approaches in the Architectural Design Studio Developing Architectural Designs Using the Solar Envelope Method

\section{Suggestions:}

The project working areas can be selected from more easily controllable places. It is important to work on areas of sizes that are suitable to the project topic. It is difficult for students to carry out projects on areas that are too big to work for a limited time on one's own.

In addition to the size of the area, the characteristics of the close surroundings should also be taken into consideration, as these help define the volume of the solar envelope. Unnecessarily small volumes should not be allowed.

The architectural project can be developed by a group. Especially when an extensive architectural requirement program is needed, the quality of the design can be significantly improved when working in a group consisting of two or three students.

It is important to turn theoretical information into practice. In the schools of architecture, students should be given the opportunity to try different methods and architectural design approaches, so that they can use them in their projects. This study is an example of this. The gained experience should be shared in academia in order to ensure an increase in awareness regarding architecture.

\section{REFERENCES}

Canan, F., Korumaz, M. \& Güleç, S.A. (2006). Vision evaluation of the Students in architecture about sustainable architecture in a local context in Konya / Turkey, Proceedings PLEA 2006, Hes.So, Université de Genève, Vol.2, pp. 785 -791.

Canan, F. (2008). A trial of model for controlling the parameters in energy efficient architectural design, PhD thesis, Selçuk University, Graduate School of Natural and Applied Sciences, Konya.

Çakmak Yılmaz, B. (2015). Solar Energy Potential of Konya and Architectural Design Criterias for Solar Energy Efficiency, International Conference on Renewable Energy Research and Applications (ICRERA), Palermo.

Capeluto, I.G. \& Shaviv, E. (2001). On the use of solar volume for determining the urban fabric, Solar Energy, Vol. 70-3, pp. 275280.

Capeluto, I.G. (2003). Energy performance of the self- shading building envelope, Energy and Buildings, Vol. 35, pp. 327-336.

Capeluto, I.G., Yezioro, A. Bleiberg, T. \& Shaviv, E. (2006). Solar rights in the design of urban spaces, Plea 2006, Proceedings PLEA 2006, Hes.So, Université de Genève, Vol.1, pp. 689-694. 
Cotton, J.F. (1996). Solid modeling as a tool for constructing solar envelopes, Automation in Construction, Vol. 5, pp. 185-192.

De Herde, A. \& Dartevelle, O. (2010). U.C.L. and sustainable architecture education in Belgium, Le Carré Bleu, Feuille Internationale d'Architecture, No. 3-4, pp.53-56.

Dimitrova, E. (2014). The 'sustainable development' concept in urban planning education: lessons learned on a Bulgarian path, Lournal of Cleaner Production,Vol. 62, pp. 120-127.

El- Zeiny, R.M.A. (2010). Sustainability in the Education of Interior designers in Egypt, Procedia - Social and Behavioral Sciences, Vol. 38, pp. $122-131$.

Forwood, B. (1994). Expressing sustainability in architectural form: energy and environment as architectural metaphors, Renewable Energy, Vol. 5, part 2, pp. 1132-1134.

Karol, E. (2006). Using campus concerns about sustainability as an educational opportunity: a case study in architectural design, Lournal of Cleaner Production, Vol. 14, pp. 780-786.

Granadeiro, V., Duarte, J. P., Correia, J.R. \& Leal, V.M.S. (2013). Building envelope shape design in early stages of the design process: Integrating architectural design systems and energy simulation, Automation in Construction, Vol. 532, pp.196-209.

Houpert, D. (2003). Approche inverse pour la résolution de contraintes solaires et visuelles dans le projet architectural et urbain- développement et application du logiciel SVR. Université de Nantes, thèse de doctorat, Ecole Doctorale Mécanique, Thermique et Génie Civil, Nantes.

Khan, A.Z., Vandevyvere, H. \& Allacker, K. (2013). Design for the ecological age, rethinking the role of sustainability in architectural education, Journal of Architectural Education, Vol. 67:2, pp. 175-185.

Knowles, R.L. (1981) Sun rhytm form. Massachusetts: The Massachusetts Institute of Technology Press.

Knowles, R.L. (2003). The solar envelope: its meaning for energy and buildings, Energy and Buildings Vol. 35, pp. 15-25.

Lefèvre, P. \& D' Orazio, A. (2010). L'enseignement de l'architecture durable en France : l'experience de vingt ans d'enseignement a l'ecole d'architecture de Paris la Villette, Le Carré Bleu, Feuille Internationale d'Architecture, No. 3-4, pp. 23-32.

Lenzholzer, S. \& Brown, R.D. (2013). Climate-responsive landscape architecture design education, Journal of Cleaner Production, Vol. 61, pp. 89-99. 
The Implementation of Sustainable Approaches in the Architectural Design Studio Developing Architectural Designs Using the Solar Envelope Method

Littlefair, P. (1998). Passive solar urban design: ensuring the penetration of solar energy into the city, Renewable and Sustainable Energy Reviews, Vol. 2, pp. 303-326.

Maciel, A.A., Ford, B. \& Lamberts, R. (2007). Main influences on the design philosophy and knowledge basis to bioclimatic integration into architectural design- The example of best practices, Building and Environment, Vol. 42, pp. 3762-3773.

Morello, E. \& Ratti, C. (2009). Sunscapes: 'Solar envelopes' and the analysis of urban DEMs, Computers, Environment and Urban Systems, Vol. 33, pp. 26-34.

Noble, D. \& Kensek, K. (1998). Computer generated solar envelopes in architecture, The Journal of Architecture, Vol. 3, pp. 117-127.

Paramitaa, B. \& Koerniawan, M.D. (2013). Solar envelope assessment in tropical region building case study: vertical settlement in Bandung, Indonesia, Procedia Environmental Science, Vol. 17, pp. 757 - 766.

Pereira, F.O.R., Silva, C.A.N. \& Turkienikz, B. (2001). A methodology for sunlight urban planning: a computer based solar and sky vault obstruction Analysis, Solar Energy, Vol. 70, pp. 217-226.

Perrin, N. (2004). Approche inverse pour la résolution de contraintes structurelles dans le projet architectural. Ecole Nationale Supérieure d'Architecture de Nancy. mémoire de DEA, Centre de Recherche en Architecture et Ingénerie, Nancy.

Raboudi, K., Belkaïd, A. \& Ben Saci, A. (2012). Satisfaction of the solar bounding box constraints, Proceedings PLEA 2012, Centro de Investigación de la Arquitectura y la Ciudad, PUCP.

Siret, D. (1997). Propositions pour une approche déclarative des ambiances dans le projet architectural- application à l'ensoleillement, Université de Nantes-Isitem, Ecole d'Architecture de Nantes, thèse de doctorat, Nantes.

Siret, D., Houpert, S. (2004). A geometrical framework for solving sunlighting problems within CAD systems, Energy and Buildings, Vol. 36, pp. 343-351.

Siret, D., Harzallah, A. (2006). Architecture et contrôle de l'ensoleillement. International Building Performance Simulation Association Conferencs (IBPSA), Saint Pierre, Réunion. 
Taleghani, M., Ansari, H. R. \& Jennings, P. (2011). Sustainability in architectural education: a comparison of Iran and Australia, Renewable Energy, Vol. 36, pp. 2021-2025.

Topaloğlu, B. (2003). Solar envelope and form generation in architecture, Middle East Technical University, master thesis, the Graduate School of Natural and Applied Sciences, Ankara.

Yannas, S. (2010). La formation a la conception durable au Royaume Uni, Architectural Association School of Architecture London, UK, Le Carré Bleu, Feuille Internationale d'Architecture, No. 3-4, pp.43-52.

Yüksek, I. (2013). The Evaluation of architectural education in the scope of sustainable architecture, Procedia -Social and Behavioral Sciences, Vol. 89, pp. 496 - 508.

Wright, J. (2003). Introducing sustainability into the architecture curriculum in the United. States, International Journal of Sustainability in Higher Education, Vol. 4, No. 2, pp. 100-105.

\section{RESUME}

Fatih Canan, Graduated from the department of architecture of Selçuk University in 1997. He obtained his European Master degree in architecture and sustainable development from Ecole Polytechnique Fédérale de Lausanne (EPFL) in 2001 and his PhD degree from Selçuk University in 2008. Currently, Canan is holding the position of Assist. Prof. Dr. in Selçuk University, Department of Architecture. His domain of research is sustainable architecture.

M. Bahadır Tosunlar, graduated from Eskişehir Osmangazi University, Department of Architecture in 2006. He worked for various positions in field of architecture. Afterwards, He received master's degree in 2015 from Selçuk University Institute of Science by completing Architectural Restoration Master Programme. Currently, Tosunlar is holding the position of research assistant in Selçuk University, Department of Architecture and continues doctorate in Selçuk University Architectural Restoration Phd Programme. 